\title{
Winning Hearts, Minds and Sales: \\ How Marketing Communication Enters the Purchase Process \\ in Emerging and Mature Markets
}

\begin{abstract}
Consumers differ in the way their minds and hearts respond to marketing communication. Recent research has quantified effectiveness criteria of mindset metrics, such as brand consideration and liking, in the purchase process for a mature market. This paper develops and illustrates our conceptual framework of how mindset effectiveness differs in an emerging and a mature market. We propose that the responsiveness, stickiness and sales conversion of mindset metrics depend on the regulative, cultural and economic systems that provide structure to society. In particular, we focus on regulative protection, collectivism and income. First, we propose that a lack of regulative protection leads consumers to be more attentive to, and thus more aware of marketing communication. Second, we propose that consumers living in a collectivist culture are less responsive to advertising in their consideration and liking of the advertised brand. Finally, we propose that lower income reduces the sales conversion of brand liking.

We examine our predictions empirically with data for the same brands in the same time period in Brazil and the United Kingdom. First, we find that brand liking has a higher responsiveness to advertising, a higher stickiness and a higher sales conversion in the U.K. versus Brazil. Thus, the advice to focus on the emotional brand connection is more appropriate in the analyzed mature versus the emerging market. In contrast, knowing the brand is more important to purchase in Brazil, and is more responsive to advertising. These first findings set up an intriguing research agenda on winning hearts and sales in emerging and mature markets.
\end{abstract}

Keywords: emerging market, institutional context systems, consumer mindset metric, brand attitudes, marketing-attitude responsiveness, attitude-sales conversion, econometric models, hierarchical linear model 
"Marketing principles are universally applicable, and the marketer's task is the same whether applied in Dimebox, Texas or Katmandu, Nepal."(Cateora \& Hess, 1966, p. 4)

"Consumers in emerging markets are more likely to talk about any kind of online advert than their counterparts in mature markets.” (Mindshare, 2011)

\section{Introduction}

Both the opportunities and the threats of increasing globalization have created an urgency for companies to succeed in international markets (Burgess \& Steenkamp, 2006; Chao, Samiee, Sai, \& Yip, 2003). Companies from mature markets strive to gain hearts and sales in emerging markets, which will account for most of the economic growth in the next decades (ibid). For example, General Motors and Peugot have struggled to obtain a share of the Chinese market (Biziouras \& Crawford 1997; Engardio, Kripalani, \& Webb, 2001), at least partly because of cultural misunderstandings (Chen, 2001). At the same time, brands from emerging markets, such as Lenovo and Haier, struggle to succeed in mature markets (Pukthuanthong \& Roll, 2009) at least partly because they lack a strong emotional connection to their customers (Lindstrom, 2011; Wang, 2008). The opening quotes illustrate the clash between views that marketing principles are universally applicable and observations of different consumer's responsiveness to marketing communication. Is it truly the case that, also in emerging markets, "building consumer hearts and minds" (Kotler \& Pfoertsch, 2010) translates into higher sales? Can systematic differences in emerging versus mature markets, help us predict how marketing communication enters the purchase process and converts into sales? These are the questions that guide us in this paper.

Despite considerable research on emerging markets, important knowledge gaps remain on whether and how marketers can influence consumer perceptions, attitudes and intentions - all of which we refer to as "consumer mindset". While some researchers find that cognitive decision processes are universal across consumers (e.g., Aaker \& Maheswaran, 1997; Douglas \& Craig, 1997), they leave open the possibility of substantial differences in the 
extent to which the process components influence purchase, and the power of marketing to affect this process. Such issues are largely unanswered in cross-cultural marketing research, which has focused on country-of-origin effects, consumer perception of local versus global bands (e.g., Batra, Ramaswamy, Alden, Steenkamp, \& Ramachander, 2000; Ozsomer, 2012; Steenkamp, Batra, \& Alden, 2003) and the content of advertising appeals (e.g., Aaker \& Williams, 1998; Han \& Shavitt, 1994). Though important, these factors do not address a more general question: should brand managers focus on moving the needle on different aspects of consumers' mindset in emerging versus mature markets? Recent conceptual papers hint this may be the case: Burgess and Steenkamp (2011), and Cayla and Arnould (2008) highlight cultural differences in the importance of individual versus group decision making as a key reason for different branding strategies in emerging versus mature markets. What is currently missing is a conceptual model and empirical approach to analyze these differences and provide guidance to marketers aiming to grow brand sales in emerging and mature markets.

We propose that marketing effectiveness differs in the extent to which consumers (1) become aware of marketing communication, (2) are open to change their minds and hearts and (3) change their buying patterns accordingly. These properties may differ from consumer (group) to consumer (group) within a country, but also should systematically differ among consumers coming from a mature versus an emerging market. If this is the case, conceptual arguments and findings regarding consumer attitudes and behavior based on mature markets may not hold in emerging markets. Key examples include the mandate that brands should be romantic and mysterious 'love marks' (Roberts, 2005), and the finding that brand liking is very responsive to advertising and converts strongly into sales (Hanssens, Pauwels, Srinivasan, \& Vanhuele, 2010). Based on the three "pillars of institutions" in institutional context theory (Burgess \& Steenkamp, 2006; Scott, 2001), we propose that differences in regulative, cultural and economic systems reduce the generalizability of such findings. We 
analyze the extent of consumer protection as the regulative factor. As a key cultural difference, we focus on Hofstede's (1980) individualism/collectivism dimension, and incorporate income level as the economic factor. Differences along these three systems translate into specific propositions on the marketing responsiveness and sales conversion of consumer mindset metrics.

Our contributions are twofold. First, we provide a unifying conceptual framework to translate consumer differences into observable criteria of market-level mindset metrics. Second, we empirically demonstrate the proposed differences in a longitudinal hierarchical linear model estimated on a unique dataset containing marketing, sales and consumer mindset metrics in Brazil and the U.K. As an initial test of our framework, this empirical study provides novel insights on how marketing enters the purchase process in a major emerging and a major mature country market.

The remainder of this paper moves from the research background to our conceptual framework and hypotheses. Next, we proceed with the empirical analysis that tests hypotheses on the level of market-aggregate metrics for the countries of Brazil and the U.K. After reporting the results, we broaden the specific findings into more general insights on how to both advance research and to help brands thrive in emerging and mature markets.

\section{Research Background and Conceptual Development}

We base our conceptual framework on the three "distinct but interrelated pillars of institutions that provide structure to society" (Burgess \& Steenkamp, 2006, p. 341), identified as vital elements of a country's institutional context in socioeconomic theory (e.g., Etzioni \& Lawrence, 1991; North, 1990; Scott, 2001). Among regulative, cultural and economic system factors, we focus on respectively consumer protection, individualism and income level. Next, we review the recent development of effectiveness criteria for mindset metrics. Combining 
both building blocks, we propose our conceptual framework of how institutional context differences affect mindset metric effectiveness criteria in an emerging versus a mature market. From this framework, we derive specific hypotheses for our empirical setting of a major emerging market (Brazil) versus a major mature market (the United Kingdom).

\subsection{Regulative, Cultural \& Economic System Differences}

As part of the regulative context, consumer protection against poor-quality products appears especially relevant to our study of how consumers respond to marketing communication. Lack of such protection is a key example of an 'institutional void' typically found in product markets of emerging countries (Khanna \& Palepu, 2010). Beyond the existence of quality and safety regulations, Khanna and Palepu (2010) also ask: "How do the authorities enforce regulations?", "What recourse do consumers have against false claims or defective products?", "Can consumers easily obtain unbiased information about the quality of the goods and services they want to buy?" and "Are there independent consumer organizations and publications that provide such information?". Marketing literature has long demonstrated that quality uncertainty increases consumers' risk perceptions, which leads them to search for more quality information before purchase (Erdem, Swait, \& Valenzuela, 2006; Money, Gilly, \& Graham, 1988; Shimp \& Bearden, 1982). In contrast, consumers enjoying strong protection may "assume that all brands offered by mainstream retailers deliver the same basic quality" (Hollis, 2010).

As to culture, one of the main issues facing all societies is to define the nature of the relation between the individual and the group (Schwartz, 1999). Researchers have labeled this tension as: independent versus interdependent self-construal (Doi, 1986; Markus \& Kitayama, 1991), individualism versus collectivism (Hofstede, 1980), separateness versus interdependence (Kagitcibasi, 2005) and autonomy versus relatedness (Schwartz, 1999). 
Following Hofstede (1980), we use the term "individualism" to identify the relative emphasis on the individual versus the larger social group. People in individualist cultures believe that individual is the most important unit. They are self-oriented, make their decisions based on individual needs and independently pursue their own ideas and preferences. Conversely, people in collectivistic cultures believe that group is the most important unit. They are grouporiented, their decisions are based on what is best for the group and, identifying with the group and participating in its shared way of life, they find meaning in life largely through social relationships (Hofstede, 1980). Individualism-collectivism is "perhaps the most central dimension of cultural variability identified in cross-cultural research" and has inspired a substantial body of research in marketing (Aaker \& Maheswaran, 1997, p. 315). Practical implications for managers are detailed in e.g., Wang's (2006) distinction of how L'Oreal should implement different branding strategies in an individualist versus collectivist society.

As to the economic context, gross domestic product (GDP) per capita, or other measures expressing purchase power, has long been used as a defining difference of mature versus emerging country markets (World Bank, 2010). Compared to the more complicated human development index of the United Nations, the GDP per capita criterion is easier to use and is more directly relevant to marketing as it focuses on available monetary resources in the country (Burgess \& Steenkamp, 2006). When GDP per capita is low, it is harder for consumers to 'follow their heart': no matter how much consumers love a brand, they will not buy it if it is not affordable (Pfeiffer, Massen, \& Bombka, 2007). Even for products considered low-ticket in mature markets, price can be an important purchase obstacle for emerging market consumers, despite their positive disposition towards the brand (Steenkamp \& Burgess, 2002). 


\subsection{Consumer Mindset Metrics and their Effectiveness Criteria}

Marketing literature is rich in conceptualization and measurement of consumer mindset metrics, such as communication awareness, brand awareness, brand consideration, brand liking, brand preference, etc. Although there is consensus that these metrics in general help detect and understand the process from brand exposure to purchase (Keller \& Lehmann, 2006), debate has raged over which metrics matter (e.g., Lautman \& Pauwels, 2009) and over whether the metrics fit into an hierarchical, linear 'purchase funnel' (e.g., Palda, 1964) or operate in a parallel fashion, as suggested by neuroscience (e.g., Rose, 1993). Empirical evidence indicates that (1) communication awareness, brand consideration and brand liking metrics substantially improve the predictive power of marketing models (Srinivasan, Pauwels, \& Vanhuele, 2010) and (2) parallel impact of such metrics predicts sales better than any hierarchy does (Vakratas \& Ambler, 1999). We maintain these assumptions in our model.

For marketing to effectively change behavior, consumers need to become aware of marketing communication, need to be open to change their minds and hearts, and consequently their buying patterns. The first part refers to the responsiveness of communication awareness ${ }^{1}$ to marketing communication. The second part refers to the responsiveness of brand attitudes, such as brand consideration and brand liking. Srinivasan et al. (2010) and Hanssens et al. (2010) propose consideration (set inclusion) to represent the 'cognitive' dimension; i.e. consumers' minds, and the extent of brand liking to represent the 'affective' dimension; i.e. consumers' hearts. Finally, the third part refers to the sales conversion of communication awareness, brand consideration and brand liking (ibid).

\footnotetext{
${ }^{1}$ Communication awareness is preferred over brand awareness in both recent academic studies on mindset metrics (Srinivasan et al., 2010; Hanssens et al., 2010) because (1) it is often used in practice to assess the effectiveness of communication campaigns, (2) it does not suffer from the variability and ceiling issues common to brand awareness (almost everyone is aware of the top brands, so the measure varies little from $99 \%-100 \%$ ).
} 
Recently, Hanssens et al. (2010) operationalized effectiveness criteria for consumer mindset metrics to capture their (1) responsiveness to marketing, (2) stickiness and (3) sales conversion. First, responsiveness is measured as the elasticity of each mindset metric to marketing, accounting for diminishing returns as the mindset metric runs out of potential to grow (e.g., 99\% awareness). Second, stickiness refers to the staying power of a change in the mindset metric, in the absence of further marketing effort. It is measured in a regression of the mindset metric on its own past. Finally, sales conversion is measured as the elasticity of brand sales to each mindset metric. Managers are urged to focus on marketing actions that generate a large response in a mindset metric that has high staying power and converts strongly into sales.

\subsection{Conceptual Framework and Hypotheses}

Figure 1 displays our conceptual framework. Starting from differences in regulative protection, individualism and income levels; we propose different responsiveness, stickiness and sales conversion of mindset metrics in an emerging versus a mature market.

\section{---- Insert Figure 1 around here ----}

Our framework is general, as are the conceptual arguments for our hypotheses. Moreover, we built on previous findings from several emerging and mature markets (e.g., Erdem et al., 2006; Hult et al., 2000; Money et al., 1988; Nicholls et al., 1997), reflecting the view that similarities in institutional context abound among countries within each group (Steenkamp \& Burgess, 2006). At the same time, we acknowledge substantial differences within emerging, and within mature markets. Therefore, any empirical analysis can only provide a partial assessment of the framework and should formulate hypotheses specific to the analyzed markets. We provide a first empirical assessment with the specific institutional context differences between Brazil (a major emerging market) and the United Kingdom (a major 
mature market). Our interest generates from the distinct differences between the average Brazilian and the average U.K. consumer on the three institutional context dimensions.

First, the Brazilian consumer enjoys less consumer protection against poor-quality products than the U.K. consumer: in Brazil, the Consumer Protection Code, which establishes basic consumer rights and sets penalties for infractions, was introduced only in 1990 (Pinto, 2002). In the U.K., such regulations were enacted in the 1970s (Beale, 1978). Proteste, the Brazilian Association of Consumer Protection, celebrated its $10^{\text {th }}$ birthday in 2011 (http://www.proteste.org.br/), while Consumer's Union celebrated its $75^{\text {th }}$. The U.K. also has a designated government office to deal with consumer complaints: the Office of Fair Trading, established by the Fair Trading Act of 1973. In contrast, the 1990 Consumer Protection Code in Brazil only establishes the Consumer Protection National System, which loosely combines the country's and civil society's efforts, leaving consumer protection "without a specific centralization" (Pinto, 2002, p. 17). Due to regional disparities, lack of resources and commercial pressure, Pinto (2002) concludes that, despite progress, "in several layers of society, citizens still ignore their basic consumer rights" (p. 31). This lack of consumer protection reflects the regulative context in general: LaPorta et al. (1998) score the U.K. 10/10 for efficiency of judicial system against 5.75/10 for Brazil, while the Global Corruption Report (2008) gives U.K. 7.7/10 and Brazil 3.5/10 (with 10 meaning 'highly clean').

How would these differences in regulative protection affect the consumers' purchase process? On the one hand, consumers may trust marketing communication less as they enjoy less protection against misleading marketing. However, empirical studies consistently show that consumers in emerging markets pay more attention to marketing communication and trust marketing messages more than their counterparts in mature markets (Eisend \& Knoll, 2012; Mindshare, 2011; Möller \& Eisend, 2010; Nielsen Media Research, 2009). For instance, $74 \%$ of consumers in Latin America (77\% in Brazil) trust TV advertising, against 
only $49 \%$ in the EU (Nielsen Media Research, 2009). Likewise, 82\% of consumer in Latin America agreed with the statement that "by providing information, advertising allows for better consumer choices", against $50 \%$ in the EU (ibid). These recent numbers support the argument that the information function of marketing is higher in emerging markets (Burgess \& Steenkamp, 2006). In a caveat emptor (buyer beware) environment, the buyer is the main responsible for ensuring that product quality meets minimum standards (Andaleeb \& Anwar 1996; Qu, Ennew \& Sinclair, 2005). Concerns to avoid poor quality products induce consumers to attend more to communication on the quality of brands (Erdem et al., 2006). Due to the responsiveness to marketing communication, future marketing stimuli will weaken the recall of the current stimulus (Burke \& Srull, 1988; Keller, 1987). As a result, increases in communication awareness are harder to maintain in the absence of repetition, leading to lower stickiness. Combining our predictions with the current situation of regulative protection in Brazil and the U.K., we propose that:

Hypothesis 1: For Brazil versus the U.K., communication awareness is (a) more responsive to marketing communication, and (b) less sticky.

Second, on Hofstede's (1980) individualism scale, Brazil scores 38 and the U.K. 90 out of 100. We posit that individualism affects the responsiveness of brand attitudes to marketing communication. Living in a highly individualist culture, U.K. consumers see themselves as independent and distinct from the group, and place high value on uniqueness, individual accomplishments and achievement. As a result, they should feel free to change their own brand attitudes substantially based on marketing communication. In contrast, Brazilian consumers see themselves as part of a larger group, value connectedness, conformity and are integrated into strong, cohesive in-groups. As a result, they should be less willing to change their attitudes based solely on marketing communication. Instead, their attitude changes mostly derive from social interaction: "if a symbol is to convey meaning, it must be identified 
by a group $[\ldots]$ and the symbol must convey similar meaning to all within the group" (Grubb \& Grathwohl, 1967, p. 24).

The few empirical papers on the subject attest to the notion that marketing communication is less important than social influence for consumers in collectivist cultures. Nicholls, Roslow, and Dublish (1997) find that Hispanic customers are more susceptible to social influences than their Anglo counterparts in the U.S. Likewise, Money et al. (1988) report that consumers in collectivist cultures rely more on interpersonal information exchange or word-of-mouth. Brands that are considered expert and trustworthy are more valuable in collectivist cultures consumers because they help reinforce group identity (Erdem et al., 2006; Johansson, Ronkainen, \& Czinkota, 1994). This anchoring of brand attitudes in the group or community also implies that, when a brand does succeed in improving attitudes, this change is rather enduring, i.e. sticky. We thus predict the following hypotheses on the basis of our conceptual framework:

Hypothesis 2: For Brazil versus the U.K., brand attitudes consideration and liking are (a) less responsive to marketing communication, and (b) more sticky.

Finally, income plays a key role in the conversion of brand liking into purchase. Poorer consumers spend a large part of their income on daily-use products (World Bank, 2010). Many economic studies have found that low-income consumers make more rational versus emotional purchase decisions (Jones \& Mustiful, 1996). Low-income consumers focus on value and product functionality (Cayla \& Arnould, 2008), which drive brand consideration (Kardes, Kalyanaram, Chandrashekaran, \& Dornoff, 1993; Roberts \& Lattin, 1991). In contrast, brand love is driven by self-brand integration, passion, separation distress, romance, mystery and sensuality (Batra, Ahuvia, \& Bagozzi, 2012; Roberts, 2005). High-income consumers have the luxury to buy the brands they love, because they spend a small 
proportion of their income on consumer products. Moreover, high-income consumers tend to gain greater command of their own information environments and are more likely to rely on their own brand liking in their purchase decision (Bennett, 1998; Giddens, 1991). Comparing Malaysia with France, Hult et al. (2000) find that consumers in the lower-income country place more importance on tangible attributes, such as price or safety. Given that the per capita Gross Domestic Product per capita (PPP) is $\$ 10,800$ for Brazil versus $\$ 34,800$ for the U.K. (World Factbook, 2011), we posit that:

Hypothesis 3: For Brazil versus the U.K., brand liking has a lower sales conversion.

We summarize the conceptual arguments and our specific hypotheses in Table 1.

---- Insert Table 1 around here ----

\section{Empirical Study}

Our conceptual framework may be falsified by different data collection methods, including experiments, surveys and purchase behavioral data. Several data providers have measured consumer attitudes at the market or segment level for decades, and have achieved adequate representation and sample sizes. The resulting metrics (including price image, communication awareness, consideration and liking) predict sales (Lourenço, 2011; Hanssens et al. 2010, Srinivasan et al. 2010, Van Heerde, Gijsbrechts, \& Pauwels, 2008). Moreover, managers are encouraged to use such mindset metrics to evaluate the success of their marketing communication actions (Keller \& Lehmann, 2006, Pauwels \& Joshi 2011). Despite the benefits of external validity and actionability, these data also have drawbacks: they are not available at the individual consumer level and constructs cannot be manipulated.

The level of analysis is an important choice: once we move beyond the individual consumer level, we can formulate hypotheses for groups of consumers, whether these are 
subcultures within a city (e.g., Ackerman \& Tellis, 2001), age cohorts within a country (e.g., Inglehart \& Baker, 2000) or countries (e.g., Hofstede, 1980; Schwartz, 1999). The latter level of analysis is typical in cross-cultural research and has the benefit of currently available data on marketing communication spending, mindset metrics and sales. Moreover, previous literature has established average levels of individualism/collectivism, consumer protection and income at the country level. These benefits come at a cost: analysis at the country level masks differences among regions within a country, and among consumers within a region.

Our empirical study combines archival sales and marketing information with largesample survey data on consumer attitudes at the country level, for Brazil and the U.K. These markets are of commercial interest because they represent a major emerging and a major mature market, each of which place in the top 10 in the category's worldwide consumption.

\subsection{Data}

The dataset contains 72 monthly observations on marketing actions (price, distribution and advertising), sales, and mindset metrics (communication awareness, brand consideration and brand liking) for 6 brands in Brazil and 10 brands in the U.K. The operationalizations follow standard practice: sales and prices are expressed in ounces of the product, distribution is All Commodity Value (ACV) distribution in the country and advertising is measured in Gross Rating Points (GRPs). To control for inflation, we calculate relative price as brand price divided by category price. The mindset metrics are similar to those in Srinivasan et al. (2010), as detailed in Table 2.

---- Insert Table 2 around here ----

Monthly sample sizes for these mindset metrics exceed 200 in each country, and quota sampling ensures that sampled respondents are representative for the country's consumers in 
the category. This characteristic increases the comparability between the emerging market and the mature market sample (Sekaran, 1983) and the managerial relevance of our findings.

The data provider requires confidentiality regarding the identity of the personal care category, and that of its brands, which are formulated and positioned either for males or for females. Table 3 presents the descriptive statistics on each variable for all advertised brands.

\section{---- Insert Table 3 around here ----}

We observe that the U.K. has four more advertised brands; 3 male and 1 female. While there is thus more competition in the U.K. market, it is not the case that its market is mature while the Brazilian market is in the early life cycle stages: in both countries, the category was introduced over 3 decades ago, but category sales and most brand sales (and market share) series are evolving ${ }^{2}$. Moreover, each brand in each market has at least one evolving mindset metric. As to the change direction, the data period sees brands both growing and shrinking in sales and in mindset metrics. Mindset metrics are not systematically lower in Brazil; i.e. they are not further away from their maximum potential of $100 \%$. Thus, while Brazil as a country may have more market potential, the analyzed brands also have plenty of room to grow in the U.K., both in consumer hearts and minds as in sales.

Six brands (three for males and three for females) are present in both markets, and they have similar sales rank, relative price and global ad campaigns for Brazil and the U.K. Male brand 1 (MB1) leads in sales, but challenger MB2 advertises more and obtains higher communication awareness. Female brand 1 (FB1) has higher sales and attitude values than FB2 and FB3. Both MB3 and FB3 are growing brands aiming to establish themselves.

\footnotetext{
${ }^{2}$ We both perform the augmented Dickey Fuller (ADF) test, which has evolution as the null hypothesis, and the Kwiatkowski, Phillips, Schmidt and Shin (KPSS) test, which has stationarity as the null hypothesis.
} 


\subsection{Methodology}

Our empirical methodology starts from Hanssens et al. (2010): they specify separate regressions for responsiveness of each mindset metric, for stickiness of each mindset metric, and for the sales conversion of the mindset metrics. They also note an important methodological issue: while sales conversion of mindset metrics is likely a characteristic of the consumer decision process in the category (and the country), responsiveness to marketing is likely brand-specific. Thus, we need to account for both country market and brand variation in the coefficients relevant to our hypotheses.

Hierarchical Linear Models (HLMs) are designed to analyze multilevel data (Draper, 1995) and can incorporate heteroscedasticity and dependence. The HLM's mathematical form enables researchers to investigate the underlying theory about the functional relationship among the variables in each level (Heck \& Thomas, 2000). The variance of an outcome variable is partitioned into "between" and "within" variances, which should increase the precision of estimates. In matrix form, the general specification is:

$$
y=X \beta+Z u+\varepsilon
$$

where $y$ is an $n x 1$ vector of responses, $X$ is an $n x p$ matrix containing the fixed effect regressors, $\beta$ is a $p \times 1$ vector of fixed effects parameters, $Z$ is an $n \times q$ matrix of random effects regressors, $u$ is a $q x 1$ vector of random effects, and $\varepsilon$ is an $n x 1$ vector of errors.

In our three-level model, time series observations within brands constitute the first level, the brands constitute the second level, and the markets constitute the third level. As a result of this hierarchical structure, the model analyzes the brands in common across countries. We fit HLM by combining fixed and random effects. We allow for random effects at both the 
market $^{3}$ and the brand-within-market levels. We choose the higher likelihood model among 1) the Varying-intercept (random-intercept) model, 2) the Varying-intercept and varyingcoefficient (random-intercept and random-slope) model. Summing up the random and fixed effects, we derive separate values for the coefficients of interest for Brazil and the U.K.

Responsiveness is the response of each mindset metric to marketing. As do Hanssens et al. (2010), we use the multiplicative model and incorporate diminishing returns by expressing the dependent variable as an odds ratio of the mindset metric (e.g., $60 \%$ awareness) and its remaining potential (e.g., $100 \%-60 \%=40 \%$ potential). The HLM specification is:

$$
y_{i j k}=\alpha+\beta_{i j[k]} X_{i j k}+\zeta_{j k}^{(2)}+\zeta_{k}^{(3)}+\varepsilon_{i j k}
$$

where $y$ is the $\log$ of odds ratio $[\mathrm{Y} /(100 \%-\mathrm{Y})]$ and $Y$ the mindset metric, $X$ are the logs of marketing (relative price, distribution and advertising GRPs). The index $i$ is for time series observations, $j$ for brands, and $k$ for markets. $\zeta_{k}^{(3)}$ is the random intercept for markets $k, \zeta_{j k}^{(2)}$ is the random intercept for brand $j$ and market $k$. Finally, $\varepsilon_{i j k}$ is the residual error and $\beta_{i j[k]}$ are the responsiveness coefficients of interest. As do Hanssens et al. (2010), we run the model separately for each mindset metric (communication awareness, brand consideration, brand liking).

Stickiness is captured by an autoregressive (AR) process $^{4}$, i.e. regressing each mindset metric on its own lagged value ${ }^{5}$. The stickiness value acts as a multiplier for translating shortterm into long-term gain. For stickiness values of $0.9,0.8$ and 0.5 respectively, one multiplies

\footnotetext{
${ }^{3}$ We formulate our model in general terms (with random component at the market level), so that researchers may use it in future applications with several emerging and mature markets. It is feasible even for our 2-market level analysis because, in the longitudinal HLM, time is nested within the brand, which is nested within the market. Thus we have not 2 (number of markets) observations but $2 * 6$ (number of brands per market)*69 (number of data periods) $=828$ observations for estimation.

${ }^{4}$ We note that we use each variable in levels in the HLM models, obtaining comparable and interpretable findings. Differencing a mindset metric before including it in the equation would limit the interpretation of our results. We thank an anonymous reviewer for this insight.

${ }^{5}$ While Hanssens et al. (2010) use an AR(3) model, we estimate an AR(1) model because (1) we need to compare a coefficient and its standard error across brands and countries and (2) we verified that the empirical ordering of brands and countries in stickiness is unchanged whether one uses the AR(1) or the AR(3) model.
} 
the short-term gain in the mindset metric by $10[=1 /(1-0.9)], 5$, and 2 respectively, to obtain the long-term gain without any further stimulation. The HLM specification is:

$$
y_{i j k}=\alpha+\beta_{i[j k]} x_{i j k}+\zeta_{j k}^{(2)}+\zeta_{k}^{(3)}+\varepsilon_{i j k}
$$

where $x$ is the lagged dependent variable, and $\beta_{i[j k]}$ the 'stickiness' coefficient of interest, which varies across markets and as well as across brands.

We assess sales conversion in a single model, in which we allow for each attitude to influence sales (Hanssens et al. 2010; Vakratsas \& Ambler, 1999). This also makes it possible to empirically test for e.g., a higher sales conversion of liking in the U.K. versus Brazil, but a lower conversion of communication awareness. The HLM specification is:

$$
y_{i j k}=\alpha+\beta_{i j[k]} X_{i j k}+\zeta_{j k}^{(2)}+\zeta_{k}^{(3)}+\varepsilon_{i j k}
$$

where $y$ is the $\log$ of sales volume, $X$ the $\log$ of each of the 3 mindset metrics, and $\beta_{i j[k]}$ the sales conversion coefficients of each mindset metric.

\section{Results}

For each of the HLM models, the Likelihood Ratio (LR) test suggests the hierarchical linear model (fixed and random specification) is superior to conventional regression (fixed effects only). Moreover, the 3-level HLM model outperforms the 2-level model, justifying the country market as a third level. Table 4 displays the percentage of variance explained by market level and by brand level differences, while tables 5-7 show the detailed estimation results for respectively responsiveness, stickiness and sales conversion. Finally, Table 8 combines fixed with random effects to present the elasticities for Brazil and the U.K.

---- Insert Tables 4-8 around here --- 


\subsection{HLM results on responsiveness}

First, for communication awareness, $3.870 \%$ of the variation can be attributed to market differences, and $51.700 \%$ to brand differences (Table 4). We thus observe a high residual variance $(44.430 \%)$ in explaining communication awareness; apparently factors other than marketing actions influence whether survey respondents recall having seen marketing communication. Relative price (0.681) and distribution (0.299) have similar effects on communication awareness in each country (Table 8). In contrast, the advertising GRP coefficient is significantly different across country markets: the average brand manages to increase communication awareness with advertising in Brazil (0.009), but not in the U.K. ($0.027^{6}$ ). In support of Hla, we thus find that responsiveness of communication awareness to ad GRPs is higher for Brazil versus the U.K.

For brand consideration, $0.367 \%$ of its variance is explained by differences between markets, $90.100 \%$ by brand differences and the remainder by residual variance (Table 4 ). Summing up the fixed and the random effects between markets (Table 8), we find that the responsiveness of brand consideration to relative price $(-0.231)$ does not differ significantly between markets, but that Brazil shows a significantly higher responsiveness to distribution (0.312 versus 0.260 ), while the U.K. shows a significantly higher responsiveness to advertising GRPs (0.009 versus 0.007$)$. Second, for brand liking, $2.225 \%$ of its variance is driven by market differences and $87.509 \%$ by brand differences. The responsiveness of brand liking to relative price (0.127) does not significantly differ across markets, but Brazil shows a significantly lower responsiveness to distribution (0.054 versus 0.100$)$ and to advertising GRPs (-0.002 versus 0.004). Thus, we find support for hypothesis H2a: the

\footnotetext{
${ }^{6}$ The negative sign is unexpected, but holds up in our robustness checks for outliers, functional form and potential multicollinearity. We infer that the specific advertising during the data period may have been very ineffective in the U.K. and thus did not add to communication awareness, while the negative estimate is due to random error in respondents' survey answers.
} 
responsiveness of brand attitudes (i.e., consideration and liking) to marketing communication is lower in Brazil versus the U.K.

Figure 2 visualizes the differences between Brazil and the U.K. regarding advertising responsiveness of mindset metrics. Communication awareness is more responsive to advertising in Brazil, but both brand attitudes (consideration and liking) are more responsive to advertising in the U.K. Advertising's main power in Brazil is to increase communication awareness, while its main power in the U.K. is to increase consideration directly.

---- Insert Figure 2 around here ---

\subsection{HLM results on stickiness}

For communication awareness, $13.869 \%$ of the variance is explained by market level differences, and $12.385 \%$ by brand difference (Table 4). In support of hypothesis H1b, communication awareness is less sticky (Table 8) in Brazil (0.611) versus the U.K. (0.878). Absent new stimuli, gains in communication awareness enjoy a multiplier of 2.571 [1/(10.611)] in Brazil, and 8.197 in the U.K.

For brand consideration, $0.218 \%$ of variance is explained by market differences, and $74.179 \%$ by brand differences. The stickiness of brand consideration is not significantly different for Brazil (0.499) versus the U.K. (0.486). For brand liking, $92.516 \%$ of variance is explained by market differences and only $4.079 \%$ by brand differences. Brand liking has significantly lower stickiness in Brazil (0.184) than in the U.K. (0.759); contrary to our hypothesis. Gains in brand liking enjoy a multiplier of $1.225[1 /(1-0.184)]$ in Brazil, and 4.149 in the U.K. Thus, we fail to find support for hypothesis $H 2 b$ that brand attitude stickiness is higher in Brazil versus the U.K. 
Figure 3 visualizes the differences in mindset metric stickiness for Brazil versus the U.K. With the exception of consideration, the staying power of mindset metrics is higher in the U.K. than it is in Brazil.

---- Insert Figure 3 around here ---

\subsection{HLM results on sales conversion}

The conversion of consumer attitudes into brand sales shows average elasticities (Table 7) of 0.133 for communication awareness (significant at the 5\% level), 0.400 for brand consideration and 0.879 for brand liking (both significant at the $1 \%$ level). These estimates are lower than, but in the same order as the average elasticities Srinivasan et al. (2010) report for France: 0.44 for communication awareness, 0.78 for brand consideration and 1.03 for brand liking.

The importance of market variation is striking for the sales conversion equation: 98.574 $\%$ of variance is explained by market differences, and $0.447 \%$ by brand differences (Table 4 ). Thus, sales conversion depends on the country, not on the specific brand. The low error $(0.979 \%)$ in the sales conversion equation implies that a given change in a mindset metric (e.g., 10\% increase) has about the same sales effect at any time in our data period. We do find significant differences across markets both in the intercept and the coefficients for communication awareness and brand liking. First, the intercept differs much more between markets than between brands (their standard deviation is respectively 3.637 and 0.246 in Table 7). The baseline of sales conversion is significantly lower in Brazil (3.836) than in the U.K. (11.103), which likely reflects the lower average income level (Table 8). As for the slope coefficients, the sales conversion of brand consideration is slightly higher in Brazil (0.401 versus 0.399$)$, but this difference is not statistically significant. However, the sales conversion of communication awareness is significantly higher in Brazil (0.185 versus 
0.081), and the sales conversion of brand liking is significantly higher in the U.K. (1.171 versus 0.613). Thus, in support of hypothesis 3, brand liking converts less to sales in Brazil than in the U.K. In addition, communication awareness is more important to sales in the U.K. than in Brazil.

Figure 4 visualizes the differences between Brazil and the U.K. regarding the sales conversion of mindset metrics. In each country, the conversion ordering is the same: upperfunnel metric communication awareness has the lowest sales conversion, followed by consideration and then liking. The marked difference is that communication awareness has more than twice the sales conversion in Brazil versus the U.K., while liking has almost twice the sales conversion in the U.K. versus Brazil.

\section{---- Insert Figure 4 around here ---}

\subsection{Managerial Implications}

How can managers use the kind of elasticities provided in Table 8? The estimated elasticities for each arrow in our Figure 1 may be combined to assess the expected sales gain of contemplated marketing actions in different countries. For example, increasing distribution by $10 \%$ increases liking by $.540 \%$ in Brazil (Table 8), but by $1.000 \%$ in the U.K. Due to the higher Liking Stickiness in the U.K., this translates into a long-term Liking gain of $.662 \%$ in Brazil and $4.149 \%$ in the U.K. Finally, due to the higher sales conversion of liking in the U.K., this long-term liking increase translates into a long-term sales gain of $.406 \%$ in Brazil versus $4.859 \%$ in the U.K. Similar calculations for communication awareness and consideration reveal a sales gain of $1.422 \%$ and $2.497 \%$ in Brazil versus $1.985 \%$ and $2.018 \%$ in the U.K., respectively. From this analysis, managers learn that the sales impact of distribution occurs mostly through Liking in the U.K., but mostly through consideration and communication awareness in Brazil. This knowledge helps them to focus on the most relevant mindset metrics in each market. Moreover, the elasticity magnitudes provide 
benchmarks for any specific marketing campaign in each market. For instance, it appears illadvised to criticize a Brazilian manager for failing to increase liking (which is key to sales gain in the U.K.); instead the focus in Brazil should be communication awareness and consideration gains. Thus, our model enables managers to prioritize different metrics in different markets instead of a one-size-fits-all.

\section{Discussion and Conclusion}

This paper presented and illustrated a conceptual framework of how effectiveness criteria for consumer mindset metrics operate differently in an emerging and a mature market. Based on regulative, cultural and economic differences between countries, we formalized our hypotheses on (1) the responsiveness and stickiness of communication awareness, (2) the responsiveness and stickiness of brand attitudes, and (3) the sales conversion of brand liking. As a first empirical assessment of the framework, we analyze these effects for a major emerging market, Brazil, versus a major mature market, the United Kingdom.

We find support for hypotheses HIa, H1b, H2a and H3. Brand attitudes consideration and liking are less responsive to marketing communication in Brazil than they are in the U.K. Brand liking has a lower sales conversion, while communication awareness has a higher sales conversion in Brazil than in the U.K. Moreover, communication awareness has a higher responsiveness to advertising in Brazil, which is the likely reason for its lower stickiness (Bettman, 1979; Burke \& Srull, 1988). However, low responsiveness to advertising does not necessarily imply high stickiness: contrary to $H 2 b$, brand liking is less sticky in Brazil than in the U.K. This may be due to the dynamic demographics in Brazil, which has both a younger population than the U.K. (Worl Factbook, 2012) and witnesses a fast rise of the middle class (Broide, Hoefel, \& Stul, 2012). As a result of such demographics, many consumers in emerging markets are first-time buyers in a product category (Batra, 1999; Burgess \& 
Steenkamp, 2006). Such dynamic demographics may lead to higher instability in the brand liking metric. Future research is needed to examine whether the lower stickiness of liking also applies to other emerging markets.

How would our results hold up in other emerging and mature markets? Our framework is general, so we would predict the same responsiveness and conversion differences for emerging (mature) markets low (high) in regulative protection, individualism and income. However, different combinations of these institutional context factors would generate interesting new predictions. For instance, Spain scores relatively low among mature markets on Hofstede's (1980) individualism scale (51/100, ranked 20th), while India scores relatively high among emerging markets (48/100, ranked $\left.21^{\text {st }}\right)$. At the same time, regulative protection and income differ substantially between these two countries, consistent with the U.K.-Brazil difference. Would Spain and India show similar advertising responsiveness of brand attitudes, but different advertising responsiveness of communication awareness, and different sales conversion of liking? Our framework would predict so, and future research is needed to verify this prediction. The regulative protection and income factors offer the additional benefit of studying changes over time, as the gap between emerging and mature markets is more likely to shrink on those institutional context dimensions than on the cultural factor (Inglehart \& Baker, 2000). If consumers in an emerging country receive much better regulative protection against poor quality products, would they start paying less attention to marketing communication? And if economic prospects substantially deteriorate in a mature market, will the sales conversion of liking decline? These predictions derive from our framework, which requires further empirical validation. Below we discuss important research and managerial implications if such validation is successful. 
Regarding the advice for brands to become "romantic and mysterious" love marks (Roberts, 2005), our findings imply that the rewards of such strategy may be much greater in a mature market like the U.K. than in an emerging market like Brazil. Indeed, the recent empirical finding that brand liking is highly responsive to advertising and converts strongly into sales (Hanssens et al., 2010) come from a country (France) where most consumers are high in individualism, income and protection against poor-quality products. Our findings give reason to believe that the Hanssens et al. (2010) result may not hold for consumers low in individualism and/or income. In our study, price increases liking, but decreases consideration. Just as Ferrari may be loved but remain out of reach for many in mature markets, relatively expensive packaged good brands may be liked by emerging market consumers who do not consider buying them in the foreseeable future.

The lower sales conversion of brand liking also implies that a strong emotional connection with consumers may not be as important for brands in emerging markets as it is for brands in mature markets (though we acknowledge that, also in mature markets, several brands with a utilitarian focus succeed ${ }^{7}$ ). In this context, Western branding experts should exercise care when claiming that "China has no brands in any real sense" (Yong, 2005) and that Chinese consumers are "unable to define the features of a brand" as "the emotional connection is simply absent" (Lindstrom, 2011). We thus agree with Cayla and Arnould (2008, p.7) to question the assumption of prominent marketing practitioners and academics that "the principles of building a strong brand are basically the same across cultures". Likewise, brands born in emerging markets should be wary of carrying their assumptions into mature markets. For example, Hyundai now recognizes the need in the US market to move beyond a "left-brain choice" (value, fuel economy, lengthy warranty) and started to show ads

\footnotetext{
${ }^{7}$ We thank the editors for this insight.
} 
that "aim to add an emotional connection and remind people that buying a Hyundai isn't just a rational choice" (Ad Age, 2011).

What does this mean for marketing managers? First, patience is gold in an emerging market like Brazil: managers should immediately track whether consumers received the message, but then need to give the social influence process time to flourish. Second, a pulse of GRP spending should allow marketing communication to start the social influence process, which then requires little if any further stimulation due to the effect of word-of-mouth and stickiness in brand consideration. Third, a large portion of the marketing budget should aim to ensure that relevant consumer groups are aware of and consider the brand for purchase.

Our framework and empirical analysis have several limitations that require further investigation. First, we base our propositions on consumer mindset (demand-side) metrics, without explicitly accounting for supply-side considerations such as infrastructure and political stability, or company factors such as organizational absorption of the marketing concept (e.g., Nakata \& Sivakumar, 2001), managerial focus (e.g., Adler \& Bartholomew, 1992, Morris \& Pitt, 1994; Peterson, 1993) and degree of marketing program standardization (Jain, 1989). Second, our focus on aggregate-level mindset metrics requires us to infer the impact of individual consumer characteristics - controlled experiments are needed to directly demonstrate these links. Third, we use specific operationalizations of regulative, cultural and economic dimensions, and future research may investigate other measures. We do not expect our findings to be sensitive to alternative operationalizations - for one, we obtain similar results substituting Hofstede's (1990) individualism-collectivism scales with Schwartz's (1999) autonomy versus relatedness scales. Fourth, our empirical study only considers one product category in one emerging versus one mature market. Further studies are needed to determine the generalizability of our findings across markets and categories. Fifth, we base our empirical analysis on the same mindset metrics for the emerging and the mature market. 
Different mindset metrics could play a key role in emerging markets. Sixth, consumer heterogeneity is substantial in both analyzed countries, thus further research may distinguish among regions, age cohorts and consumer segments. Last but not least, the question remains whether differences in mindset dynamics and marketing effectiveness are mostly driven by institutional, cultural or economic differences. The economic gap between currently emerging and mature markets may disappear within the next decades, but the cultural differences are likely to remain (Inglehart \& Baker, 2000). As countries transition from industrial to serviceoriented economies, will consumers continue go for 'safe bets', i.e. brands with reliable quality and good service (Zhou, 2008) or will they go for 'love marks', i.e. brands that are "romantic, sensual and intimate" (Roberts, 2005)? Time will tell how this romance versus reliability dilemma will continue to evolve. 


\section{References}

Aaker, J. L., \& Maheswaran, D. (1997). Effects of cultural orientation on perception. Journal of Consumer Research, 24, 315-328.

Aaker, J. L., \& Williams, P. (1998). Empathy versus pride: the influence of emotional appeals across culture. Journal of Consumer Research, 25, 241-261.

Ackerman, D., \& Tellis, G. (2001). Can culture affect prices? A cross-cultural study of shopping and retail prices. Journal of Retailing, 77, 57-82.

Ad Age. (2011). Hyundai Marketing Boss: We're Not Just a 'Left-Brain' Choice. accessed October 12, 2011: http://adage.com/article/news/hyundai-marketing-boss-a-left-brain-choice /230305/?utm_source=cmo_strategy\&utm_medium=newsletter\&utm_campaign=adage

Adler, N. J., \& Bartholomew, S. (1992). Academic and professional communities or discourse: generating knowledge on transnational human resource management. Journal of Business Studies, 23, 551-569.

Andaleeb, S. S., \& Anwar, S. F. (1996). Factors influencing customer trust in salespersons in a developing country. Journal of International Marketing, 4, 35-52.

Ballard, Vikki A. (2010). The Relationship Between History, Culture, and Chinese Business Practices: Using Sociological Awareness to Avoid Common Faux Pas. Undergraduate Honors Theses. Paper 42.

Batra, R. (1999). Marketing Issues and Challenges in Transitional Economies. Marketing Issues in Transitional Economies, Norwood, MA: Kluwer Academic Publishers, 3-35.

Batra, R., Ahuvia, A., \& Bagozzi, R. P. (2012). Brand love. Journal of Marketing, Vol. 76, No. 2 , pp. 1-16.

Batra, R., Ramaswamy, V., Alden, D. L., Steenkamp, J.-B. E. M., \& Ramachander, S. (2000). Effects of brand local and nonlocal origin on consumer attitudes in developing countries. Journal of Consumer Psychology, 9, 83-95.

Beale, H. (1978). Unfair Contract Terms Act 1977. British Journal of Law and Society, 5(1), 114121.

Bennett, T. (1998). Culture: A reformer's science. Thousand Oaks, CA: Sage.

Bennett, W. L., \& Manheim J. (2006). The one-step flow of communication. Annals of the American Academy of Political and Social Science, 608, 213-232.

Bettman, J. R. (1979). Memory factors in consumer choice: a review. Journal of Marketing, 43, $37-53$.

Biziouras, N., \& Crawford, B. (1997). Why Does Asia Beckon Some European Auto Firms and Not Others? An Assessment of Market and Non--Market Strategies. Berkeley, CA: UC Berkeley.

Broide, J., Hoefel, F., \& Stul, F. (2012). Getting to know you: How to reach Brazil's burgeoning middle class .McKinsey Company, accessed August 7, 2012

http://csi.mckinsey.com/knowledge_by_region/americas/how_to_reach_brazils_burgeoning_ middle_class. 
Burgess, S.M., \& Steenkamp, J.-B. E. M. (2006). Marketing renaissance: how research in emerging markets advances marketing science and practice. International Journal of Research in Marketing, 23, 337-356.

Burgess, S.M. \& Steenkamp, J.B.E.M. (2011). Call for Papers: Special Issue on Marketing in Emerging Markets. International Journal of Research in Marketing, 28, vi-vii.

Burke, R., \& Srull, T. (1988). Competitive interference and consumer memory for advertising. Journal of Consumer Research, 15, 55-68.

Cateora, P., \& Hess, J. (1966). International marketing. Homewood, IL: Irwin.

Cayla, J., \& Arnould, E. J. (2008). A cultural approach to branding in the global marketplace. Journal of International Marketing, 16, 88-114.

Chao, P., Samiee, S., Sai, L., \& Yip, C. (2003). International marketing and the Asia-Pacific region developments, opportunities, and research issues. International Marketing Review, 20, 480-492.

Chen, M. (2001). Inside Chinese Business: A Guide For Managers World. Boston, MA: Harvard Business School Press.

Doi, T. (1986). The anatomy of self. Tokyo: Kodanska International.

Douglas, S. P., \& Craig, C. S. (1997). The changing dynamic of consumer behavior: implications for cross-cultural research. International Journal of Research in Marketing, 14, 379-395.

Draper, D. (1995). Assessment and propagation of model uncertainty. Journal of the Royal Statistical Society: Series B (Methodological), 57, 45-97.

Eisend, M. \& Knoll, S. (2012): Transnational Trust in Advertising Media. Included as a book chapter in: Handbook of Research on International Advertising. Shintaro Okazaki (Editor), Edward Elgar Publishing.

Engardio, P., Kripalani, M., \& Webb, A. (2001). Smart globalization. Business Week Online 27. accessed July 7, 2011: http://www.businessweek.com/magazine/content/01_35/b3746653.htm.

Erdem T., Swait, J., \& Valenzuela, A. (2006). Brands as signals: a cross-country validation study. Journal of Marketing, 70, 34-49.

Etzioni, A., \& Lawrence, P. R. (1991). Socio-economics: Toward a new synthesis. Armonk, NY: Sharpe.

Giddens, A. (1991). Modernity and self-identity: self and society in the late modern age. Stanford: Stanford University Press.

Global Corruption Report (2009). Corruption and the Private Sector. Cambridge University Press, New York.

Grubb, E. L., \& Grathwohl, H.L. (1967). Consumer self-concept, symbolism and market behavior: a theoretical approach. Journal of Marketing, 31, 22-27.

Han, S., \& Shavitt S. (1994). Persuasion and culture: advertising appeals in individualistic versus collectivist cultures. Journal of Experimental Psychology, 30, 326-350. 
Hanssens, M. D., Pauwels, K., Srinivasan, S., \& Vanhuele, M. (2010). Consumer Attitude Dynamics and Marketing Impact on Sales. Marketing Science Institute, Working Paper 10-115.

Heck, R. H., \& Thomas, S. L. (2000). Analysis of large-scale secondary data in higher education research: potential perils associated with complex sampling designs. Research in Higher Education, 42, 517-540.

Hofstede, G. (1980). Culture's consequences: international differences in work-related values. Newbury Park, CA: Sage.

Hollis, N. (2010). The differences between mature and emerging markets. Milward Brown, accessed July 4, 2011: https://www.millwardbrown.com/global/blog/Post/2010-05-06/Thedifferences-between-mature-and-emerging-markets.aspx.

Hult, G.T.M., Hurley, R.F., Giunipero, L.C., \& Nichols Jr., E.L. (2000). Organizational learning in global supply management: a model and test of internal users and corporate buyers. Decision Sciences, 31 (2), 293-325.

Inglehart, R., \& Baker, W. E. (2000). Modernization, cultural change, and the persistence of traditional values. American Sociological Review, 65, 19-51.

Jain, S. C. (1989). Standardization of international marketing strategy: some research hypotheses. Journal of Marketing, 53, 70-79.

Johansson, J. K., Ronkainen, I. A., \& Czinkota M. R. (1994). Negative country-of-origin effects: The case of New Russia. Journal of International Business Studies, 25(1), 157-76.

Jones, E., \& Mustiful B. W. (1996). Purchasing behavior of higher- and lower-income shoppers: a look at breakfast cereals. Applied Economics, 28, 131-137.

Kagitcibasi, C. (2005). Autonomy and Relatedness in Cultural Context: Implications for Self and Family. Journal of Cross-Cultural Psychology, 36, 403-422.

Kardes, F., Kalyanaram, G., Chandrashekaran, M., \& Dornoff, R. (1993). Brand retrieval, consideration set composition, consumer choice, and the pioneering advantage. Journal of Consumer Research, 20, 63-75.

Keller, K.L. (1987). Memory Factors in Advertising: The Effect of Advertising Retrieval Cues on Brand Evaluations. Journal of Consumer Research, 14 (December), 316-333.

Keller, K.L. \& Lehmann, D.R. (2006). Brands and Branding: Research Findings and Future Priorities, Marketing Science, 25 (November-December), 740-759.

Khanna, T., \& Palepu K. G. (2010). Winning in emerging markets: spotting and responding to institutional voids. Boston: Harvard Business Press.

Kotler, P., \& Pfoertsch, W. (2010). Ingredient branding: making the invisible visible. NewYork: Springer.

LaPorta, R., Lopez-de-Silanes, F., Shleifer, A. \& Vishny, R.W. (1998). Law and Finance. Journal of Political Economy. 106 (6), 1113-1155.

Lautman, M., \& Pauwels, K. (2009). What is Important? Identifying Metrics that Matter. Journal of Advertising Research, 49 (3), 339-359. 
Lindstrom, M. (2011). How the Chinese became global branding geniuses. Fast Company. accessed September 14, $2011 \mathrm{http} / / / \mathrm{www} . f a s t c o m p a n y . c o m / 1748843 / \mathrm{how}$-the-chinese-oncetone-deaf-to-brands-became-global-branding-geniuses.

Lourenço, C. J. S. (2011). Dynamic store price image formation and category pricing. Disseration, Tilburg University.

Markus, H. R., \& Kitayama, S. (1991). Culture and the self: implications for cognition, emotion, and motivation. Psychological Review, 98, 224-253.

McKinsey. (2010). A new way to measure word-of-mouth marketing, accessed February 2, 2012 http://www.mckinseyquarterly.com/A_new_way_to_measure_word of mouth_marketing_2567.

Mindshare. (2011). Emerging markets open to more online advertising. accessed July 12, 2011http://www.microsoft.com/presspass/emea/presscentre/pressreleases/EmergingMarketsA dvertising_190411.mspx.

Möller, J., \& Eisend, M. (2010). A Global Investigation into the cultural and individual antecedents of consumers' responsiveness towards banner advertisements. Journal of International Marketing, 18 (2),80-98.

Money, B. R., Gilly, M. C., \& Graham, J. L. (1988). Explorations of national culture and word-ofmouth referral behavior in the purchase of industrial services in the United States and Japan. Journal of Marketing, 62, 76-87.

Morris, M. H., \& Pitt, L. F. (1994). The organization of the future: unity of marketing and strategy. Journal of Marketing Management, 10, 553-560.

Morwitz, V., \& Schmittlein, D. (1992). Using segmentation to improve sales forecasts based on purchase intent: which 'intenders' actually buy? Journal of Marketing Research, 29, 391-405.

Nakata, C., \& Sivakumar, K. (2001). Instituting the marketing concept in a multinational setting: the role of national culture. Journal of the Academy of Marketing Science, 29, 255-75.

Nicholls, J. A. F., Roslow, S., \& Dublish, S. (1997). Time and companionship: key factors in Hispanic shopping behavior. Journal of Consumer Marketing, 14, 194-205.

Nielsen Media Research. (2009). Nielsen Global Online Consumer Survey - Trust, Value, and Engagement in Advertising. accessed March 21, 2012.http://hk.acnielsen.com/documents/NielsenTrustAdvertisingGlobalReportJuly09.pdf

North, D. C. (1990). Institutions, institutional change, and economic performance. New York: Cambridge University Press.

Ozsomer, A. (2012). The Interplay Between Global and Local Brands: A Closer Look at Perceived Brand Globalness and Local Iconness. Included as a book chapter in: Handbook of Research on International Advertising. Shintaro Okazaki (Editor), Edward Elgar Publishing.

Palda, K. S. (1964). The measurement of cumulative advertising effects. Englewood Cliffs, NJ: Prentice Hall.

Pauwels, Koen and Amit Joshi (2011), "Counting what will Count: Does your Dashboard Predict?," Asia Pacific Journal of Business, 2, 2, 1-35. 
Pauwels, K., Silva-Risso, J., Srinivasan, S., \& Hanssens, D. M. (2004). New products, sales promotions and firm value: the case of the automobile industry. Journal of Marketing, 68, 142-156.

Peterson, D. B. (1993). Skill learning and behavior change in an individually tailored management coaching and training program. Doctoral dissertation, University of Minnesota.

Pfeiffer, P., Massen, S., \& Bombka, U. (2007). Serving the low income consumer: How to tackle this mostly ignored market. ATKearney. accessed August 15,

2011.http://www.atkearney.com/index.php/Publications/serving-the-low-incomeconsumer.html.

Pinto, L. R. M. (2002). Consumer protection in Brazil: a general view. Dissertation, Institute of Brazilian Business and Public Management Issues. George Washington University.

Pukthuanthong, K., \& Roll, R. (2009). Global market integration: an alternative measure and its application. Journal of Financial Economics, 94, 214-232.

Qu, R., Ennew, C. T., \& Sinclair, M. T. (2005). The impact of regulation and ownership structure on market orientation in the tourism industry in China. Tourism Management, 26, 939-950.

Roberts, K. (2005). Lovemarks: the future beyond brands. New York: Power House Books.

Roberts, J. H., \& Lattin, J. M. (1991). Development and testing of a model of consideration set composition. Journal of Marketing Research, 28, 429-40.

Rose, S.P.R. (1993). The Making of Memory. London: Bantam Books.

Schwartz, S. H. (1999). A theory of cultural values and some implications for work. Applied Psychology: An International Review, 48 (1), 23-47.

Scott, W. R. (2001). Institutions and organizations (2nd Ed.). Thousands Oaks, CA: Sage.

Sekaran, U. (1983). Methodological and theoretical issues and advancements in cross-cultural research. Journal of International Business Studies, 14, 61-73.

Shimp, T. A., \& Bearden, W. O. (1982). Warranty and other extrinsic cue effects on consumer risk perceptions. Journal of Consumer Research, 9, 38-46.

Srinivasan, S., Pauwels, K., \& Vanhuele, M. (2010). Mindset metrics in market response models: an integrative approach. Journal of Marketing Research, 47, 672-684.

Steenkamp, J.-B. E. M, Batra, R., \& Alden, D. L. (2003). How perceived brand globalness creates brand value. Journal of International Business Studies, 34, 53-65.

Steenkamp, J. B. E. M., \& Burgess, S. M. (2002). Optimum stimulation level and exploratory consumer behavior in an emerging consumer market. International Journal of Research in Marketing, 19(2), 131-15.

Vakratsas, D., \& Ambler, T. (1999). How advertising works: what do we really know? Journal of Marketing, 63, 26-43.

Van Heerde, H., Gijsbrechts, E., \& Pauwels, K. (2008). Winners and losers in a major price war. Journal of Marketing Research, 45, 499-518. 
Wang, J. (2008). Brand new China: advertising, media and commercial culture. Cambridge, MA: Harvard University Press.

Wang, W. S. (2006). How culture influences the brand association in the United Kingdom and Taiwan: a case study of L'oreal Paris. Master Thesis, University of Central Florida.

World Bank. (2010). World Bank annual report. accessed October 12, 2011 www.worldbank.org/annualreport/2010.

World Factbook. (2011). Central intelligance agency. accessed October 12, 2011 https://www.cia.gov/library/publications/the-world-factbook/fields/2001.html\#br.

Worl Factbook. (2012). Central intelligance agency. accessed August 7, 2012. https://www.cia.gov/library/publications/the-world-factbook/geos/br.html

Yong, T. (2005). I never said that Haier and Lenovo are not brands. accessed July 7, 2011 http://english1.people.com.cn/200502/27/eng20050227_174878.html.

Zhou, L. (2008). A golden opportunity? How Chinese brands are betting on an Olympic boost. Financial Times, accessed July 15, 2011 http://www.ft.com/cms/s/0/c730720e-6962-11dd91bd-0000779fd18c.html\#axzz1bHTNqYB4. 
Table 1: Summary of Conceptual Arguments and Findings

\section{Institutional Dimension}

\section{Theoretical Argument}

How Brazil differs from the U.K.
Hypotheses

For Brazil versus the U.K.

\section{Regulative}

consumer protection against poor-quality products, including enforcing basic consumer rights and enacting penalties for infractions

(Beale, 1978; Khanna and Palepu, 2010; Pinto, 2002)

\section{Cultural}

individualism vs. collectivism: the nature of relation between the individual and the group

(Hofstede, 1980; Markus \& Kitayama, 1991; Schwartz, 1999)

\section{Economic}

gross domestic product (GDP) per capita which focuses on available monetary resources in the country (Burgess \& Steenkamp, 2006) concerns to avoid poor quality products should lead consumers to attend more to communication on the quality of brands (Erdem et al., 2006)

increases in communication awareness are harder to maintain in the absence of repetition (Burke \& Srull, 1988; Keller, 1987) collectivism implies marketing communication to be less important than social influence (Money et al., 1988;Nicholls et al., 1997)

when a brand does succeed in improving attitudes, this change is more enduring in collectivist cultures

(Johansson et al. 1994)

low-income consumers make more rational versus emotional purchase decisions

(Cayla \& Arnould, 2008; Jones \& Mustiful, 1996)

high-income consumers are more likely to rely on their own brand liking in their purchase decision (Bennett, 1998; Giddens, 1991 )

\begin{tabular}{|c|c|}
\hline $\begin{array}{c}\text { Brazilian consumers enjoys } \\
\text { less consumer protection } \\
\text { against poor-quality } \\
\text { products } \\
\text { than U.K. consumers } \\
\text { (LaPorta et al. } 1998 \text { ) }\end{array}$ & $\begin{array}{l}\text { communication awareness } \\
\text { is more responsive to } \\
\text { marketing communication } \\
\text { [H1a; supported] } \\
\text { communication awareness } \\
\text { is less sticky to marketing } \\
\text { communication } \\
\text { [H1b; supported] }\end{array}$ \\
\hline $\begin{array}{l}\text { on Hofstede's (1980) } \\
\text { individualism scale } \\
\text { Brazil scores } 38 \text { and } \\
\text { the U.K. } 90 \text { out of } 100\end{array}$ & $\begin{array}{l}\text { brand attitudes are less } \\
\text { responsive to marketing } \\
\text { communication } \\
\text { [H2a; supported] } \\
\text { brand attitudes are more } \\
\text { sticky to marketing } \\
\text { communication } \\
\text { [H2b; not supported] }\end{array}$ \\
\hline $\begin{array}{l}\text { the per capita Gross } \\
\text { Domestic Product is } \\
\$ 10,800 \text { for Brazil versus } \\
\$ 34,800 \text { for the U.K }\end{array}$ & $\begin{array}{c}\text { brand liking has a lower } \\
\text { sales conversion } \\
\text { [H3; supported] }\end{array}$ \\
\hline
\end{tabular}


Table 2: Variable Operationalization

\begin{tabular}{|l|l|}
\hline \multicolumn{1}{|c|}{ VARIABLE } & \multicolumn{1}{c|}{ OPERATIONALIZATION } \\
\hline \multicolumn{1}{|c|}{ Marketing Mix } \\
\hline Relative Price & Average price paid for 1 ounce of brand, divided by average price in category \\
\hline Distribution & All Commodity Volume (ACV) weighted distribution \\
\hline Advertising & Gross Rating Points (GRPs) of advertising \\
\hline & \\
\hline Sales & Volume sales in ounce \\
\hline
\end{tabular}




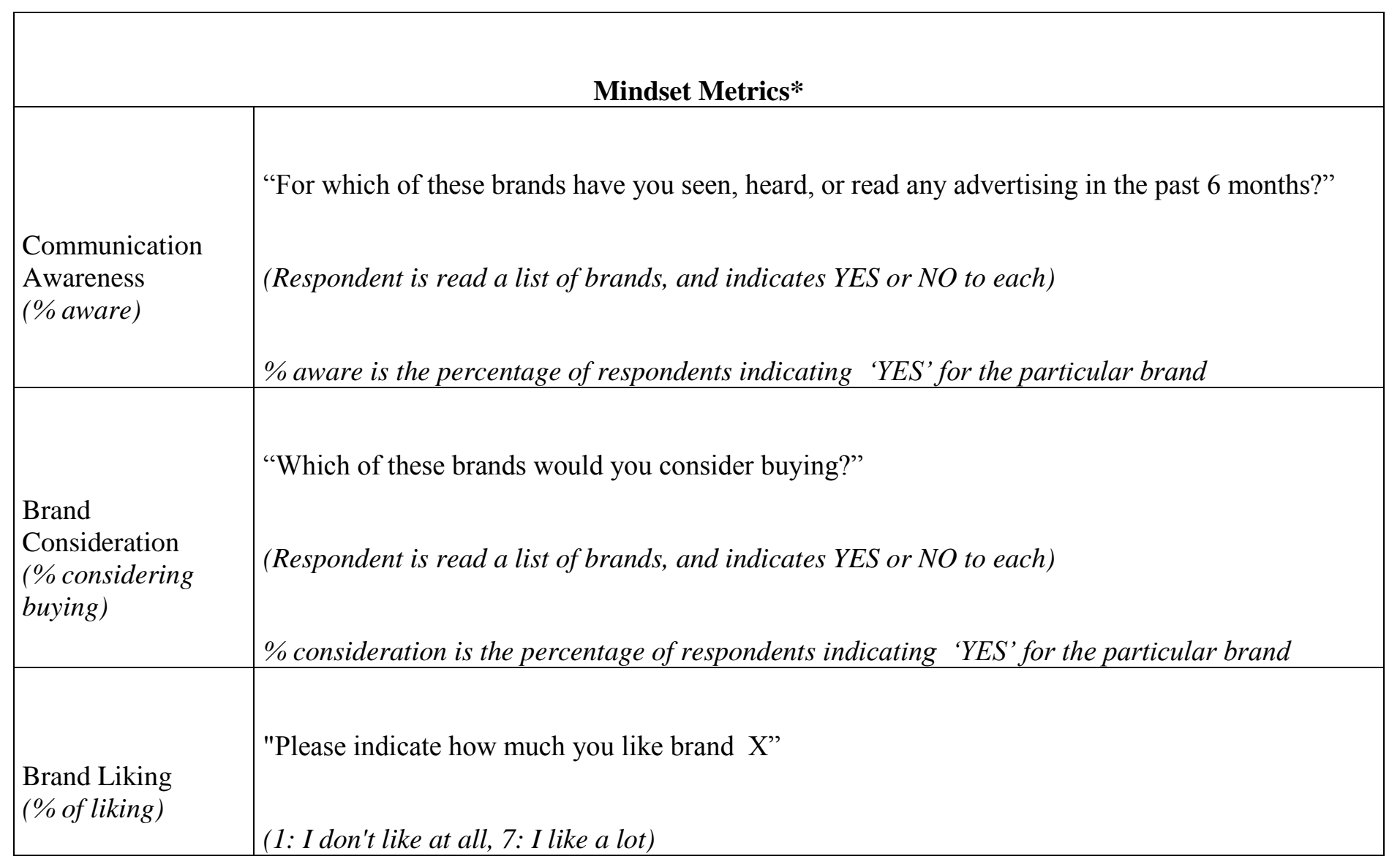

* measured every month in a stratified national sample, with between 246 and 251 respondent realized each month in Brazil, and between 243 and 249 respondents realized in the United Kingdom 
Table 3: Descriptive Statistics for Brands Present in Both Markets (Ordered by Market Share) and Remaining Brands (Ordered by Market Share)

\begin{tabular}{|c|c|c|c|c|c|c|c|c|c|c|c|c|c|c|c|c|c|c|c|c|}
\hline \multicolumn{21}{|c|}{ Brazil } \\
\hline \multirow[t]{2}{*}{ M/Female Sales Rank } & \multicolumn{2}{|c|}{ M1 } & \multicolumn{2}{|c|}{$\mathrm{M} 2$} & \multicolumn{2}{|c|}{ M3 } & & & & & & & \multicolumn{2}{|c|}{ F1 } & \multicolumn{2}{|c|}{ F2 } & \multicolumn{2}{|c|}{ F3 } & & \\
\hline & Mean & SD & Mean & SD & Mean & SD & & & & & & & Mean & SD & Mean & SD & Mean & SD & & \\
\hline CA & 39.374 & 10.260 & 49.025 & 12.387 & 30.118 & 8.2236 & & & & & & & 49.072 & 7.480 & 52.445 & 7.671 & 34.433 & 7.283 & & \\
\hline Consideration & 66.043 & 5.768 & 67.878 & 6.033 & 21.304 & 4.646 & & & & & & & 71.451 & 7.455 & 59.778 & 7.527 & 39.672 & 5.885 & & \\
\hline Liking & 26.397 & 4.826 & 25.152 & 6.745 & 6.506 & 2.353 & & & & & & & 32.765 & 7.424 & 23.183 & 4.602 & 11.831 & 3.699 & & \\
\hline Relative Price & 0.987 & 0.022 & 0.931 & 0.018 & 1.154 & 0.052 & & & & & & & 0.956 & 0.023 & 1.138 & 0.025 & 1.153 & 0.062 & & \\
\hline Distribution & 474.671 & 174.395 & 580.884 & 86.639 & 189.329 & 70.529 & & & & & & & 778.971 & 203.782 & 371.657 & 91.318 & 290.000 & 100.635 & & \\
\hline Ad GRPs per $100 \mathrm{~m}$ inhabitants & 171.293 & 280.301 & 229.043 & 282.048 & 7.480 & 32.502 & & & & & & & 349.022 & 419.444 & 239.227 & 244.876 & 102.056 & 203.101 & & \\
\hline \multicolumn{21}{|c|}{ United Kingdom } \\
\hline M/Female Sales Rank & \multicolumn{2}{|c|}{ M1 } & \multicolumn{2}{|c|}{ M2 } & \multicolumn{2}{|c|}{ M3 } & \multicolumn{2}{|c|}{ M4 } & \multicolumn{2}{|c|}{ M5 } & \multicolumn{2}{|c|}{ M6 } & \multicolumn{2}{|c|}{ F1 } & \multicolumn{2}{|c|}{ F2 } & \multicolumn{2}{|c|}{ F3 } & \multicolumn{2}{|c|}{$\mathrm{F} 4$} \\
\hline & Mean & SD & Mean & SD & Mean & SD & Mean & SD & Mean & SD & Mean & SD & Mean & SD & Mean & SD & Mean & SD & Mean & SD \\
\hline CA & 48.136 & 9.863 & 43.765 & 11.690 & 36.743 & 11.355 & 16.754 & 16.631 & 22.680 & 16.265 & 39.155 & 11.913 & 44.798 & 13.795 & 56.309 & 14.049 & 21.746 & 15.225 & 21.185 & 14.626 \\
\hline Consideration & 53.155 & 6.022 & 51.672 & 7.316 & 23.117 & 5.782 & 46.088 & 6.697 & 41.509 & 7.423 & 39.567 & 4.497 & 77.758 & 5.037 & 72.261 & 5.400 & 34.339 & 6.424 & 45.109 & 4.744 \\
\hline Liking & 15.241 & 5.893 & 29.571 & 11.254 & 21.225 & 5.214 & 12.783 & 5.465 & 8.150 & 3.467 & 9.731 & 3.425 & 22.124 & 10.789 & 23.886 & 11.269 & 7.511 & 4.874 & 9.583 & 4.831 \\
\hline Relative Price & 1.114 & 0.108 & 0.94 & 0.158 & 1.135 & 0.084 & 0.700 & 0.099 & 0.880 & 0.112 & 0.870 & 0.115 & 0.938 & 0.069 & 1.115 & 0.106 & 1.163 & 0.103 & 0.811 & 0.062 \\
\hline Distribution & 695.935 & 75.360 & 505.469 & 115.324 & 295.377 & 109.630 & 876.180 & 96.610 & 533.720 & 95.951 & 312.524 & 182.447 & 995.411 & 283.836 & 688.13 & 383.915 & 480.901 & 166.534 & 947.899 & 129.737 \\
\hline Ad GRPs per $100 \mathrm{~m}$ inhabitants & 102.717 & 182.703 & 295.477 & 248.802 & 27.246 & 72.479 & 103.049 & 139.493 & 15.572 & 61.686 & 31.269 & 83.261 & 260.320 & 315.120 & 226.168 & 214.909 & 69.682 & 132.77 & 51.007 & 107.653 \\
\hline
\end{tabular}


Table 4: Variance Partition Coefficients (in percentages) for all HLM Models

\begin{tabular}{|c|c|c|c|c|c|c|c|}
\hline & \multicolumn{3}{|c|}{ Responsiveness Equations } & \multicolumn{3}{|c|}{ Stickiness Equations } & \multirow{2}{*}{$\begin{array}{c}\text { Sales } \\
\text { Conversion }\end{array}$} \\
\hline & $C A$ & Consideration & Liking & $C A$ & Consideration & Liking & \\
\hline Market & 3.870 & 0.367 & 2.225 & 13.869 & 0.218 & 92.516 & 98.574 \\
\hline Brands & 51.700 & 90.100 & 87.509 & 12.385 & 74.179 & 4.079 & 0.447 \\
\hline Residual & 4.430 & 9.533 & 10.267 & 73.746 & 25.603 & 3.405 & 0.979 \\
\hline
\end{tabular}


Table 5: Maximum Likelihood Estimates of Responsiveness Equations in Longitudinal HLM*

\begin{tabular}{|c|c|c|c|c|c|c|c|c|c|c|c|c|}
\hline & \multicolumn{4}{|c|}{ Model 1 (DV= Log_CA) } & \multicolumn{4}{|c|}{ Model 2 (DV= Log_Consideration) } & \multicolumn{4}{|c|}{ Model 3 (DV=Log_Liking) } \\
\hline & Coefficient & $S E$ & $z$ & $p>|z|$ & Coefficient & $S E$ & $z$ & $p>|z|$ & Coefficient & $S E$ & Z & $p>|z|$ \\
\hline \multicolumn{13}{|l|}{ Fixed Effects } \\
\hline$\alpha$ & -2.366 & 0.445 & -5.31 & 0.000 & -1.989 & 0.368 & -5.41 & 0.000 & -0.296 & 0.079 & -3.73 & 0.000 \\
\hline Log_Price & 0.681 & 0.108 & 6.34 & 0.000 & -0.231 & 0.051 & -4.52 & 0.000 & 0.127 & 0.012 & 10.57 & 0.000 \\
\hline Log_Distribution & 0.300 & 0.067 & 4.48 & 0.000 & 0.286 & 0.042 & 6.75 & 0.000 & 0.077 & 0.019 & 4.12 & 0.000 \\
\hline Log_GRPs & -0.009 & 0.019 & -0.46 & 0.644 & 0.008 & 0.006 & 1.36 & 0.174 & 0.001 & 0.002 & 0.40 & 0.690 \\
\hline$\sqrt{\psi^{(2)}}$ & 0.558 & & & & 0.772 & & & & 0.163 & & & \\
\hline$\sqrt{\theta}$ & 0.522 & & & & 0.251 & & & & 0.056 & & & \\
\hline$\sigma_{\beta\left(\text { Log_Price }_{-}\right.}$ & 0.029 & & & & 0.008 & & & & 0.004 & & & \\
\hline$\sigma_{\beta(\text { Log_Distribution })}$ & 0.008 & & & & 0.038 & & & & 0.024 & & & \\
\hline$\sigma_{\beta\left(L_{\text {Log_GRPS }}\right)}$ & 0.022 & & & & 0.003 & & & & 0.003 & & & \\
\hline
\end{tabular}

$* \sqrt{\psi^{(3)}}$ is the standard deviation of the random intercept at the market level, $\sqrt{\psi^{(2)}}$ is the standard deviation of the random intercept at the brand level, $\sqrt{\theta}$ is the standard deviation of the residuals. For the responsiveness of consideration, the between-market (level 3) variance is $\sigma_{\beta(\text { Log_Price })}^{2}+\sigma_{\beta(\text { Log_Distribution })}^{2}+\sigma_{\beta\left(\text { Log_GRPS }_{-}\right.}^{2}+\psi^{(3)}=0.002$, the between-brand (level 2) variance is $\psi^{(2)}=0.596$ and the within-market between-brand (level 1) variance, i.e. the variance of the residuals is $\theta=0.063$. Thus, the total variance is $0.002+0.596+0.063=0.661$ and the between-market variance partition is $0.002 / 0.661=0.367 \%$ 
Table 6: Maximum Likelihood Estimates of Stickiness Equation in Longitudinal HLM*

\begin{tabular}{|c|c|c|c|c|c|c|c|c|c|c|c|c|}
\hline & \multicolumn{4}{|c|}{ Model 1 (DV=Log_CA) } & \multicolumn{4}{|c|}{ Model 2 (DV=Log_Consideration) } & \multicolumn{4}{|c|}{ Model 3 (DV=Log_Liking) } \\
\hline & Coefficient & $S E$ & $z$ & $p>|z|$ & Coefficient & $S E$ & $z$ & $p>|z|$ & Coefficient & $S E$ & $z$ & $p>|z|$ \\
\hline \multicolumn{13}{|l|}{ Fixed Effects } \\
\hline$\alpha$ & -0.122 & 0.060 & -2.03 & 0.043 & -0.172 & 0.175 & -0.98 & 0.327 & 0.101 & 0.031 & 3.30 & 0.001 \\
\hline $\mathrm{AR}(1)$ & 0.749 & 0.098 & 7.65 & 0.000 & 0.492 & 0.058 & 8.45 & 0.000 & 0.398 & 0.131 & 3.04 & 0.002 \\
\hline \multicolumn{13}{|l|}{ Random Effects } \\
\hline$\sqrt{\psi^{(3)}}$ & 0.016 & & & & 0.030 & & & & 0.008 & & & \\
\hline$\sqrt{\psi^{(2)}}$ & 0.133 & & & & 0.420 & & & & 0.071 & & & \\
\hline$\sqrt{\theta}$ & 0.326 & & & & 0.250 & & & & 0.055 & & & \\
\hline$\sigma_{\beta(A R(1), \text { market level })}$ & 0.129 & & & & 0.030 & & & & 0.102 & & & \\
\hline$\sigma_{\beta(A R(1), b r a n d ~ l e v e l)}$ & 0.016 & & & & 0.079 & & & & 0.233 & & & \\
\hline Log Likelihood & -133.814 & & & & -30.592 & & & & 595.698 & & & \\
\hline LR test & $\chi_{4}^{2}=12.73$ & prob > & $\chi^{2}=0$ & 013 & $\chi_{4}^{2}=76.0$ & prob > & $\chi^{2}=0$ & 000 & $\chi_{4}^{2}=71.28$, & $>\chi^{2}=$ & 000 & \\
\hline
\end{tabular}

$* \sqrt{\psi^{(3)}}$ is the standard deviation of the random intercept at the market level, $\sqrt{\psi^{(2)}}$ is the standard deviation of the random intercept at the brand level, $\sqrt{\theta}$ is the standard deviation of the residuals.

$\sigma_{\beta(A R(1) \text {,market level) }}$ is the standard deviation of the slope parameter for the lagged DV at market level,

$\sigma_{\beta(A R(1) \text {,brand level })}$ is the standard deviation of the slope parameter for the lagged DV at brand level 
Table 7: Maximum Likelihood Estimates of Sales Conversion Equation in Longitudinal HLM*

\begin{tabular}{|c|c|c|c|c|}
\hline & \multicolumn{4}{|c|}{ (DV=Log_Sales) } \\
\hline & Coefficient & $S E$ & $z$ & $p>|z|$ \\
\hline \multicolumn{5}{|l|}{ Fixed Effects } \\
\hline$\alpha$ & 7.470 & 2.574 & 2.90 & 0.004 \\
\hline Log_CA & 0.133 & 0.060 & 2.21 & 0.027 \\
\hline Log_Consideration & 0.400 & 0.064 & 6.27 & 0.000 \\
\hline Log_Liking & 0.879 & 0.261 & 3.37 & 0.001 \\
\hline
\end{tabular}

\section{Random Effects}

\begin{tabular}{ll}
$\sqrt{\psi^{(3)}}$ & 3.637 \\
$\sqrt{\psi^{(2)}}$ & 0.246 \\
$\sqrt{\theta}$ & 0.364 \\
$\sigma_{\beta(\text { Log_CA })}$ & 0.066 \\
$\sigma_{\beta(\text { Log_Consideration })}$ & 0.019 \\
$\sigma_{\beta(\text { Log_Liking })}$ & 0.292 \\
\hline \hline
\end{tabular}

\begin{tabular}{ll} 
Log Likelihood & -189.135 \\
LR test & $\chi_{5}^{2}=1802.52$, prob $>\chi^{2}=0.000$ \\
\hline
\end{tabular}

$* \sqrt{\psi^{(3)}}$ is the standard deviation of the random intercept at the market level, $\sqrt{\psi^{(2)}}$ is the standard deviation of the random intercept at the brand level, $\sqrt{\theta}$ is the standard deviation of the residuals. $\sigma_{\beta\left(\text { Log_CA }_{-}\right.}$is the standard deviation of the slope parameter for the log of Communication Awareness, etc. 
Table 8: Elasticity Estimates (combining fixed and random effects) for Brazil versus U.K.

\begin{tabular}{|c|c|c|c|c|c|c|}
\hline \multirow{5}{*}{$\begin{array}{l}\alpha \\
\operatorname{AR}(1)\end{array}$} & \multicolumn{6}{|c|}{ Stickiness } \\
\hline & \multicolumn{2}{|c|}{$\log _{-} C A$} & \multicolumn{2}{|c|}{ Log_Consideration } & \multicolumn{2}{|c|}{ Log_Liking } \\
\hline & Brazil & U.K. & Brazil & U.K. & Brazil & U.K. \\
\hline & -0.117 & -0.117 & -0.172 & -0.172 & 0.094 & 0.082 \\
\hline & 0.611 & 0.878 & 0.499 & 0.486 & 0.184 & 0.759 \\
\hline & \multicolumn{6}{|c|}{ Responsiveness } \\
\hline & \multicolumn{2}{|c|}{$\log _{-} C A$} & \multicolumn{2}{|c|}{ Log_Consideration } & \multicolumn{2}{|c|}{ Log_Liking } \\
\hline & Brazil & U.K. & Brazil & U.K. & Brazil & U.K. \\
\hline$\alpha$ & -2.363 & -2.369 & -1.990 & -1.988 & -0.295 & -0.297 \\
\hline Log_Price & 0.681 & 0.681 & -0.231 & -0.231 & 0.127 & 0.126 \\
\hline Log_Distribution & 0.299 & 0.299 & 0.312 & 0.260 & 0.054 & 0.100 \\
\hline \multirow[t]{4}{*}{ Log_GRPs } & 0.009 & -0.027 & 0.007 & 0.009 & -0.002 & 0.004 \\
\hline & \multicolumn{2}{|c|}{ Sales Conversion } & & & & \\
\hline & \multicolumn{2}{|c|}{ Log_Sales } & & & & \\
\hline & Brazil & U.K. & & & & \\
\hline$\alpha$ & 3.836 & 11.103 & & & & \\
\hline Log_CA & 0.185 & 0.081 & & & & \\
\hline Log_Consideration & 0.401 & 0.399 & & & & \\
\hline Log_Liking & 0.613 & 1.171 & & & & \\
\hline
\end{tabular}


Figure 1: Conceptual Framework and Hypotheses for Emerging Market Brazil versus Mature Market U.K.

Institutional Context

influences Effectiveness Criteria

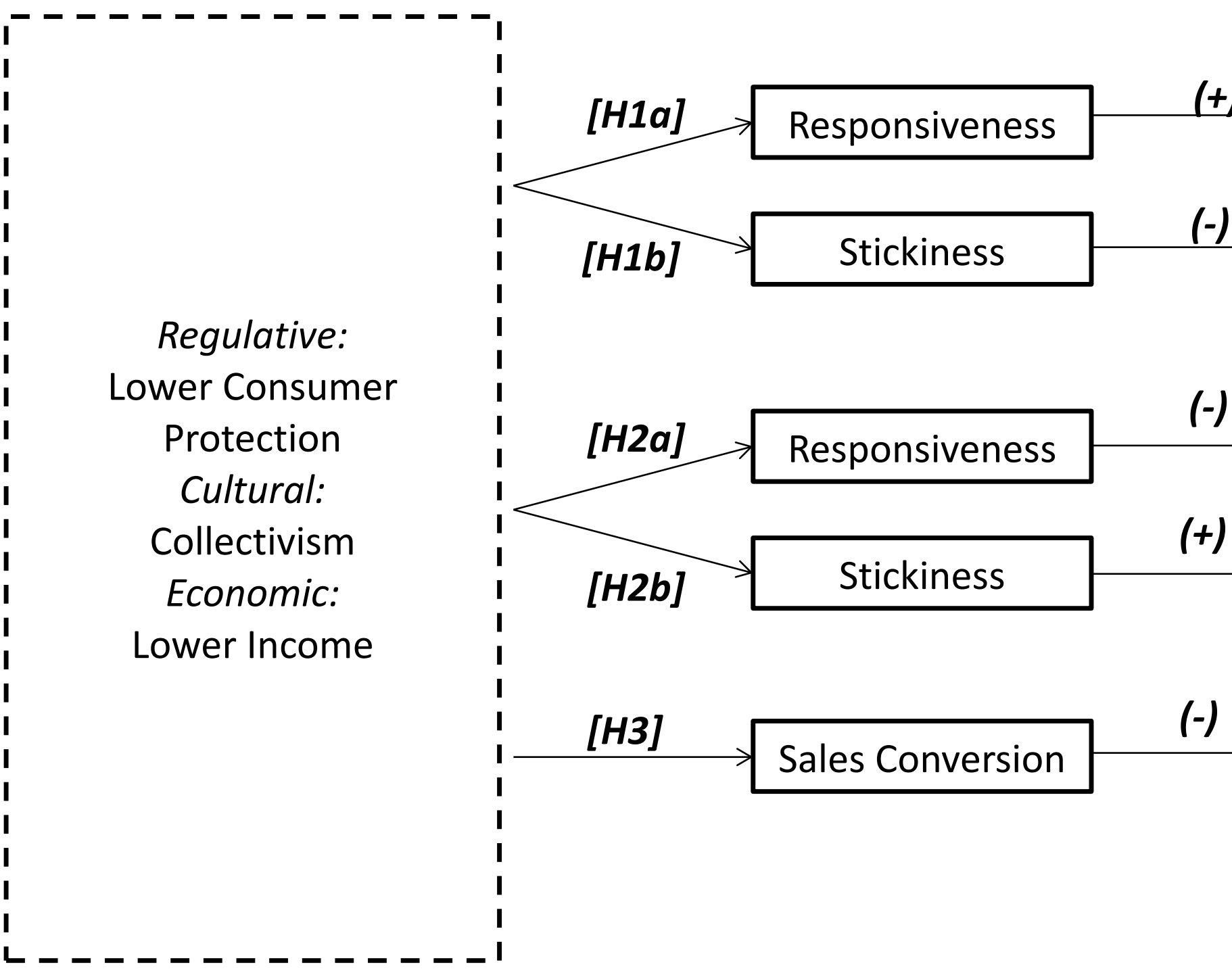


Figure 2: Advertising Responsiveness of Mindset Metrics in Brazil versus U.K.

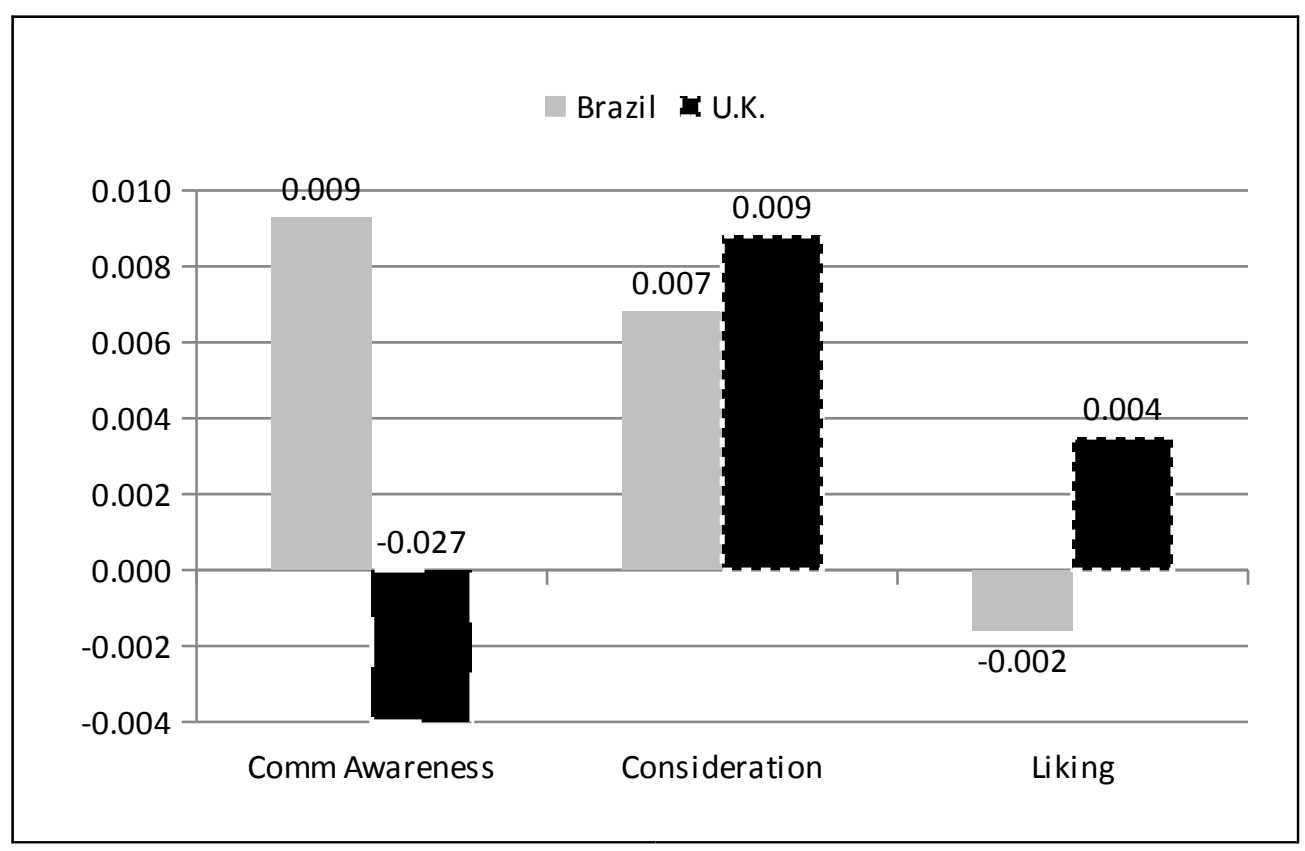


Figure 3: Stickiness of Mindset Metrics in Brazil versus U.K.

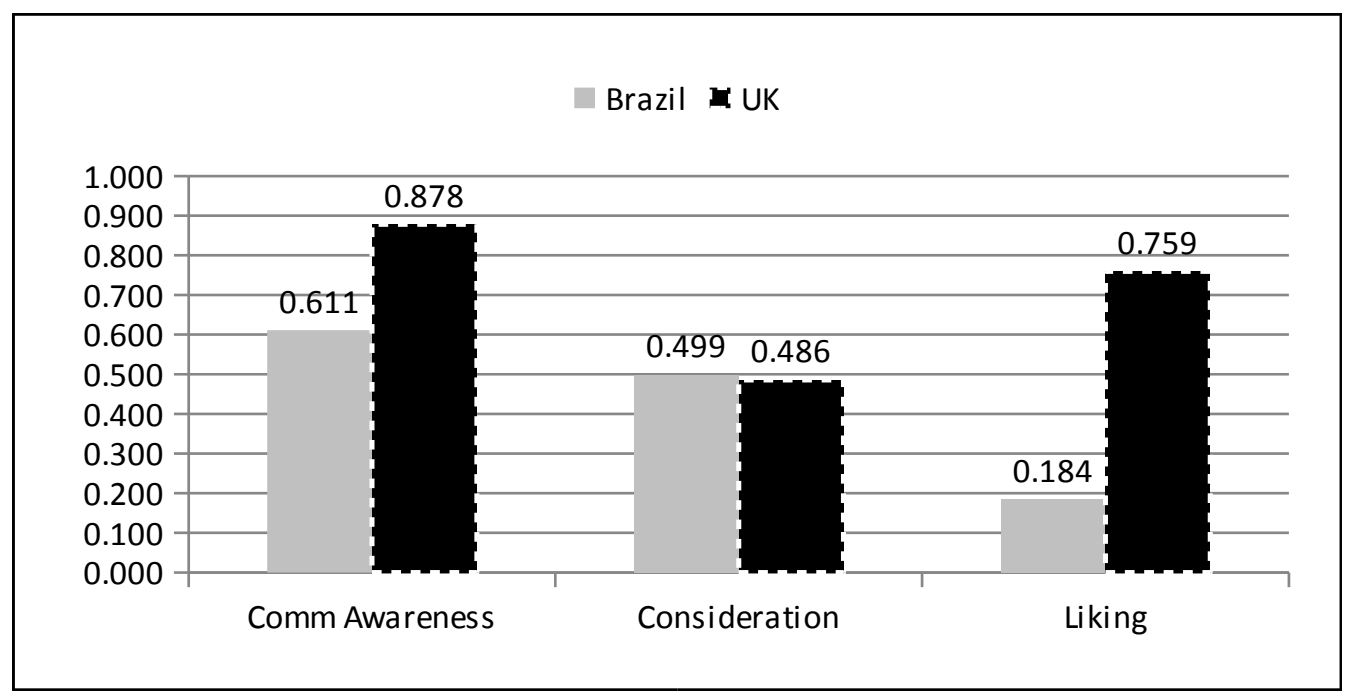


Figure 4: Sales Conversion of Mindset Metrics in Brazil versus U.K.

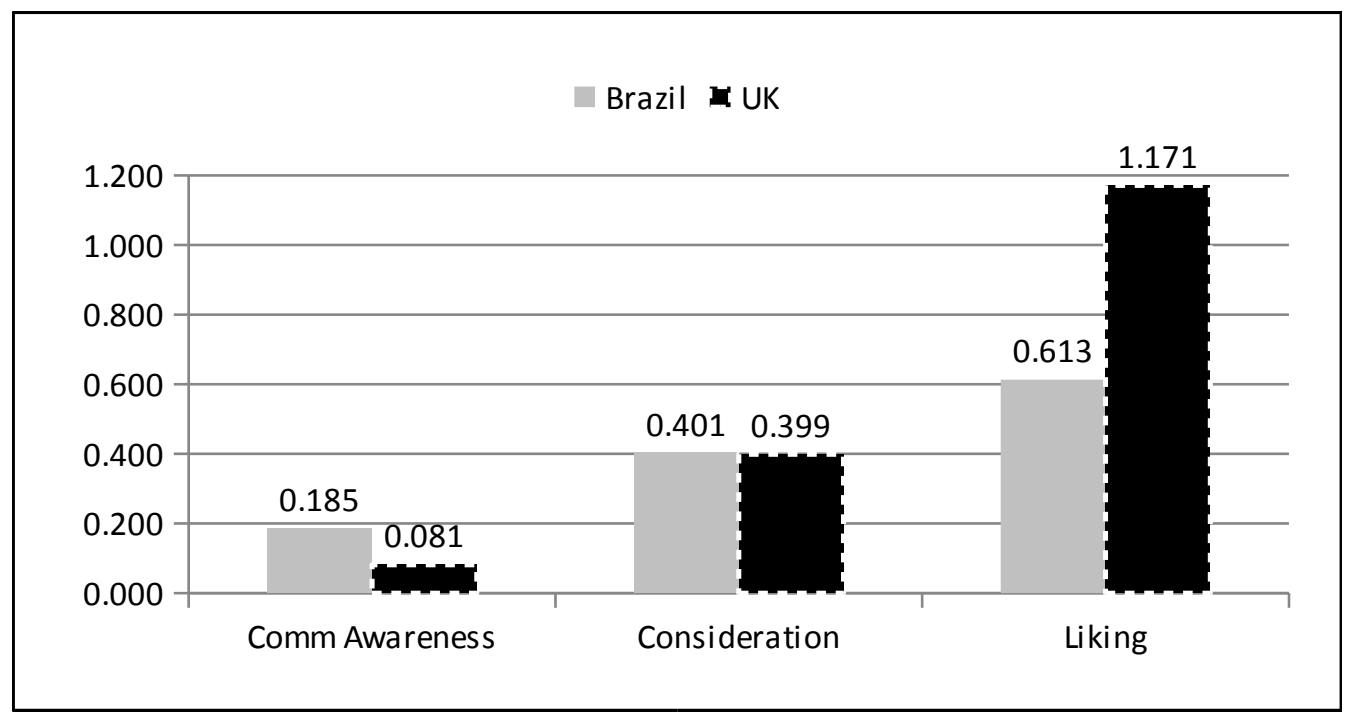

